for the $80 \%$ oxygen group) may wonder after reading the Grief paper, while munching bagels in some doctors' lounge, whether they should immediately embrace the amazing new adjunct. Who does not want to be au courant? At my institution, the wound-infection rate for colon resection over the past 10 years $(3.8 \%)$ has been measured by a rigid program of continuous, global, 30-day infection surveillance that does not depend upon culture results as confirmatory or exculpatory data. ${ }^{6}$ Should I and my partners add $80 \%$ oxygen prophylaxis for all colon resections starting tomorrow? If we do, how will we know if we used it correctly or if it had any benefit? Maybe most surgical patients at every hospital should receive $80 \%$ oxygen under the inspiration of "can't hurt, might help." There are not going to be easy answers here, but we may surmise that orders for $80 \%$ oxygen and purchases of the special masks will increase across the land real soon. I also predict much premature joy at any hospital where the natural up-down cycling of surveillance infection rates (ie, random process noise) just happens to be in its "down" mode after $80 \%$ oxygen use begins. Remember, we will be using this adjunct under nonresearch conditions, with the outcome data being estimated infection rates that come from surveillance programs already battling numerous issues of case-finding sensitivity, uniformity, and personnel budget crimps. The post hoc ergo propter hoc fallacy will be an uninvited visitor at infection control conferences.

Perceptive readers of the Grief article are going to notice one more thing. Surgeons who participated in the study achieved a $5.2 \%$ infection rate at 15 days using $80 \%$ oxygen but uniformly eschewed (as many European surgeons do) the use of orally administered, non-absorbed antibiotics as an element of preoperative colon preparation.
That thoroughly tested tactic, along with some kind of mechanical preparation of the colon, is used by a majority of surgeons in the United States in combination with intravenous antibiotic prophylaxis that covers bowel flora. Misunderstanding of this belt-and-suspenders approach is legendary. The oral antibiotic component provably reduces the level of both aerobic and anaerobic intraluminal pathogens so that any spillage of colon contents poses a smaller challenge to the patient's defenses than would stool itself. Correctly administered systemic antibiotics preload the extracellular fluid space and render it bacteria-unfriendly throughout the entire operation. Here is the punch line: we do not know, and the elaborate Grief study was unfortunately not designed to test, whether adding $80 \%$ oxygen prophylaxis to state-of-the-art colon preparation along with accurate prophylactic antibiotic infusion reduces infection risk in colon-rectal operations.

\section{REFERENCES}

1. Grief R, Akca O, Horn EP, Kurz A, Sessler DI. Supplemental perioperative oxygen to reduce the incidence of surgical-wound infection. Outcomes Research Group. N Engl J Med 2000;342:161-167.

2. Gottrup F. Prevention of surgical-wound infections. $N$ Engl J Med 2000;342:204.

3. Doyle AC. The Complete Sherlock Holmes. Garden City, NY: Doubleday and $C_{0}$, Inc; 1905:335-350.

4. Zerr KJ, Furnary AP, Grunkemeier GL, Bookin S, Kanhere V, Starr A. Glucose control lowers the risk of wound infection in diabetics after open heart operations. Ann Thorac Surg 1997;63:356-361.

5. Mangrum AJ, Horan TC, Pearson ML, Silver LC, Jarvis WR. Guideline for the prevention of surgical site infection, 1999. Hospital Infection Control Practices Advisory Committee. Infect Control Hosp Epidemiol $1999 ; 20: 250-278$.

6. Lee JT, Olson MM. Wound infection surveillance for 85,260 consecutive operations. Journal of Surgical Outcomes 1999;2:27-42.

7. Lee JT. Surgical wound infections: surveillance for quality improvement. In: Fry DE, ed. Surgical Infections. Boston, MA: Little Brown and Co; 1995:145-159.

\title{
Surgical-Site Infections in Mexico
}

\section{Gina Pugliese, RN, MS Martin S. Favero, PhD}

Vilar-Compte and colleagues from the Instituto Nacional de Cancerologia and Instituto de Investigaciones Biomedicas, Universidad Nacional Autonoma de Mexico, conducted a study to quantify the surgical infection rate and to identify risk factors associated with surgical-site infection (SSI) in a 130-bed tertiarycare teaching hospital for adult patients with cancer.

A case-control study of all surgical patients (313) was done between January 1, 1993, and June 30, 1994; the study followed 3,372 surgeries (rate/100 surgeries: 9.30 ). Risk factors associated with SSI were diabetes mellitus, obesity, presence of surgical drains for $>5$ and $<16$ days, and presence of surgical drains for $\geqslant 16$ days, similar to those previously reported. The bacteria isolated most frequently were Escherichia coli, 38 (21.8\% of the total of microorganisms found); Pseudomonas species, 22 (12.6\%); Staphylococcus aureus, 16 (9.2\%); and coagulase-negative staphylococci 25
(13.6\%). The coexistence of other nosocomial infections was greater among cases (odds ratio, 1.8; 95\% confidence interval, 1.1-3.1) than the controls.

The authors concluded that the SSI rate in their hospital is slightly higher than the rates reported for general hospitals.

FROM: Vilar-Compte D, Mohar A, Sandoval S, de La Rosa M, Gordillo $P$, Volkow P. Surgical site infections at the National Cancer Institute in Mexico: a case-control study. $A m J$ Infect Control 2000;28:14-20. 